\title{
Effectiveness of Nurses' Emotional Intelligence Training on Quality of Nursing Care for Critically Ill Patients
}

\author{
Om Hashem Gomaa Ragab ${ }^{1}$, Naglaa Gamal Eldien Abd_Elhafez ${ }^{2}$ \& Safaa Abdelaziz Rashed ${ }^{3}$. \\ 1. Lecturer of nursing administration, Faculty of nursing, Sohag University, Egypt. \\ 2. Lecturer of critical care \& emergency nursing, Faculty of nursing, Sohag University, Egypt. \\ 3. Lecturer of nursing administration, Faculty of nursing, Sohag University, Egypt.
}

\begin{abstract}
Emotional intelligence enables critical care nurses to be aware of self and others including patients' emotions result in patients' satisfaction and improved quality of care. The current study aims to determine effectiveness of nurses' emotional intelligence training on quality of nursing care for critically ill patients. Design: quasi experimental research design was used. Setting: General ICU, emergency unit, and coronary care unit at Sohag University Hospital. Sample: First group is: convenient sample of 70 nurses. Second group is: 420 patients were selected into two groups' pre and post nurses training. Tools: Quick Emotional Intelligence Self-Assessment Questionnaire and Patients' Perception of Quality Nursing Care Scale. Results: a highly significant relation between nurses' emotional intelligence level pre training with post training $\mathrm{T}$ test 3.699 at $\mathrm{P}<0.01$; a highly significant relation in patients' perception of quality nursing care $\mathrm{T}$ test 7.623 at $\mathrm{P}<0.01$; and highly significant relation between nurses' emotional intelligence level and patients' perception of quality nursing care $\mathrm{r}=0.767$ at $\mathrm{P}<0.01$. Conclusions: improvement in nurses' emotional intelligence level resulted in the improvement in the quality of nursing care. Recommendations emotional intelligence training should be introduced for critical care nurses as a basic of in-service training programs.
\end{abstract}

Key Words: Critical Care Nurses, Critically Ill Patients, Emotional Intelligence, Quality of Nursing Care \& Training.

\section{Introduction}

Critically ill patients' experience physical limitations, in addition to they feel lonely and isolated as they cannot receive needed family support. They develop cognitive impairment rapidly after ICU admission. Most common causes of cognitive impairment include delirium, hyperglycemia, hypotension, hypoxemia and sedation (Wergin and Modrykamien, 2012, Yeşil et al., 2015, Daniels et al., 2018).

Nurses should ordinarily interact with the most intense emotional aspects of life, and continuously reply to the needs of patients and families (Vahedian-Azimi et al., 2015, Shorofi et al., 2016). Physicians as well as nurses respond to emotions of critically ill patients with emotions of their own. These emotions can affect both the quality of care and the clinicians own sense of well-being, since unexamined emotions may also lead to distress, disengagement, burnout, and poor judgment. All of these consequences have a negative impact on patient care (Weilenmann et al., 2018).

Critical care nursing focuses intensively on all aspects of basic nursing care and life support, and thus combines the essence of nursing with observation, insightful and even intuitive interpretation, and reactions to the slightest imbalance or deviation in a patient's condition
(Scholtz et al., 2016) Skilled critical care nursing will reduce the risk of most complications, the number of critical care bed days and improve patient outcomes (Driscoll et al., 2018). Nurses are expected to be cheerful, responsive, kind, honest, compassionate, approachable and friendly (Sun \& Okochili, 2017). Satisfactory nurses' performance requires the use of emotional intelligence (EI) (Rezaei \& Salehi, 2018).

Emotional intelligence has important consequences for both, patients' therapeutic relationship and the nurses themselves (Al-Hamdan et al., 2017). Emotional intelligence for nurses enable to control their own emotions and correctly detect, interpret and handle the emotions of others, to identify the needs of the other person and to provide an individualized attention (Cerit \& Gordeles, 2014). Emotional intelligence can be defined as an individual's ability to perceive, control and evaluate emotions. This set of characteristics, which deal with the perception, expression and regulation of moods and emotions, suggests that there must be a direct relationship between emotional intelligence, physical and psychological health (Shahnavazi et al., 2018).

Emotional intelligence components include: Selfawareness is the ability to read one's emotions and recognize their impact while using gut feelings to guide decisions; Self-management, involves 
controlling one's emotions and impulses and adapting to changing circumstances; Social awareness includes the ability to sense, understand, and react to other's emotions while comprehending social networks; and Relationship management entails the ability to inspire, influence, and develop others while managing conflict. Emotional intelligence is further translated to five areas of competencies: selfawareness, self-regulation, motivation, empathy, and social skills. Emotional intelligence can be improved by education, practice and experience (Liu et al., 2013, Meehan et al., 2015).

Patients' perception of quality nursing care is increasingly seen as an important measure in examining quality of health care. Perception of quality nursing care influences by the expectations of the client who receives care as well as the nature of the received care. Patient as customer of care is considered an important source of information for the evaluation of existing care program and development of new one (Senarath \& Gunawardena, 2011, AlHussami et al., 2017).

\section{Significance of the study}

Nurses who possess a sufficient level of emotional intelligence are well placed to provide services in a way that improves patient satisfaction. Also, they are more skilled at managing their own emotions (Hajibabaee et al., 2018) Quality nursing care is the purpose for which nurses and administrators work out. Patients everywhere become so knowledgeable and able to identify and seek high quality nursing care. When the nurse is aware of self and others mean he/she has acceptable level of emotional intelligence the result is quality of nursing care will be positively affected. So it is important to improve the level of critical care nurses' emotional intelligence through training to improve quality of nursing care for critically ill patients.

\section{Aim of the study}

The aim of this study is to determine the effectiveness of nurses' emotional intelligence training on quality of nursing care for critically ill patients.

\section{Hypothesis}

Training for critical care nurses on emotional intelligence will result in high level of quality of nursing care for critically ill patients.

\section{Subjects \& Method \\ Research Design}

Quasi experimental research design used to conduct this study.

\section{Setting}

The current study conducted in (general intensive care unit, emergency unit, and coronary care unit) at Sohag University Hospital.

Sample

- The $1^{\text {st }}$ group is: convenient sample composed of all available nurses working in designated sites (70) and willing to participate in the study.

- The 2nd group is: a purposive sample of 420 patients divided to 2 groups was selected for pre and post applying emotional intelligence training for nurses from the previous mentioned setting. Sample size determined using scoring Epi Info program to detect sample size equal 210 for each group at power study $80 \%$ Confidence Interval CI $95 \%$. Number of patients per group per unit was (44 for General Intensive Care, 97 for Emergency, and 69 for Coronary Care Unit). Inclusion criteria: patients admitted for at least 48 hours, 18 years or older, able to communicate and willing to participate in the study.

\section{Tools}

First Tool: quick emotional intelligence selfassessment questionnaire adopted from University of Minnesota Extension (2017). The tool contains close ended questions in 2 parts: Part I covered personal characteristics age, sex, educational qualification, marital status, years of experience and unit. Part II Emotional intelligence four domains of 40 statements 10 for each domain emotional awareness, emotional management, social emotional awareness and relationship management.

The questionnaire based on five points Likert scale ranged from 0 (Never) to 4 (Always). Scoring system for each domain divided into 0-24 area for enrichment: requires attention and development; 2534 effective functioning: consider strengthening; and 35-40 enhanced skills: use as leverage to develop weaker areas. The researchers of current study added the current score for effective variation between each level of EI. The total score of 40-item range from 0 to 160; scores less than 97 are considered low level of EI, scores between 97 and 136 are average level and scores of 137 and more are high level of EI.

Second Tool: Patients' Perception of Quality Nursing Care Scale (PPQNCS) adopted from Dikmen \& Yılmaz, (2016). The questionnaire consists of two sections. $\mathbf{1}^{\text {st }}$ section is patient personal characteristics data; it includes unit name, date of unit admission, name, age, sex, marital status, level of education, and length of patient stay. $2^{\text {nd }}$ section is patients' perception of quality nursing care consists of 15 statements. The options given based on five points Likert scale ranged from 1 (strongly disagree) to 5 (strongly agree). 


\section{Methods}

The study conducted throughout three main phases, which are preparatory phase, implementation phase and evaluation phase.

Preparatory phase: through which extensive review of literature was done.

- Data collection tools translated into Arabic.

- A pilot study: conducted on 42 patients (10\%) and 7 nurses (10\%), randomly selected from intermediate intensive care unit at Sohag University Hospital, to test clarity and applicability of the study tools and time needed to fill in the questionnaire.

- Reliability of the study tools was done by Cronbach's alpha test it was 0.814 for quick emotional intelligence questionnaire selfassessment and 0.847 for Patients' Perception of Quality Nursing Care Scale.

- Jury of three professors in the field one from Nursing Administration and two from Critical Care Nursing reviewed the study tools to ensure content validity.

- Official permissions to carry out the study from the heads of designated units were done. Handout of emotional intelligence training was developed in Arabic.

\section{Implementation phase}

- Data collected within nine months from January to September 2018. Patients' perception of nursing care firstly measured from January to February.

- Then emotional intelligence training for nurses was applied as follow: the implementation of training was delivered for five months from March to July.

- Nurses were assigned into small groups, 2 or 3 nurses were included per group and seven sessions for each group were implemented. Each session took about one hour.

- At first session, assessment of nurses' emotional intelligence level was measured and quick orientation of the training program was done. Training introduced at the designated settings.

- Training booklet contained the following outlines;

- Introduction, definition of terms, quality of nursing care, employees training and its relation to quality,

- General principles of emotions, the evolution of emotional intelligence, components of emotional intelligence, what is the emotions, positive and negative questions, negative emotional feelings in the work environment and its seriousness,

- Positive criticism, emotional intelligence in the family and work, abilities and skills of person who has a high degree of emotional intelligence, disadvantages of delayed emotional maturity,
- Situations and examples that illustrate emotional intelligence and emotional regulation, situations with nursing,

- How to improve emotional maturity, and

- Patient behavior in intensive care, how to help sick person to overcome his ordeal in simple ways.

Evaluation phase

- At the end of last session, assessment of nurses' emotional intelligence level was measured again.

- Patients' perception of quality nursing care then measured post nurses training from August to September.

Ethical considerations: research proposal approved from Graduate Studies and Research Committee, faculty of nursing, Sohag University. Consent obtained from nurses and patients who are willing to participate in the study and met the inclusion criteria, after explaining the nature and purpose of the study. Confidentiality and anonymity assured.

\section{Statistical Design}

The collected data were coded entered into IBM compatible computer. All entered data were verified for any errors using Statistical Package for Social Sciences (SPSS) version 19 for windows. The collected data tabulated and analyzed using frequencies \& percentages, Pearson correlation coefficient (r), means and standard deviations, T-test and Chi-square test. Test of significance were considered as follow: insignificant $P \geq 0.05$; significant $\mathrm{P}<0.05$ and highly significant $\mathrm{P}<0.01$. 
Reslts

Table (1): Frequencies and percentages distribution of nurse's according to personal characteristics $(\mathrm{n}=\mathbf{7 0}$ nurses).

\begin{tabular}{|c|c|c|}
\hline Variable & n & $\%$ \\
\hline \multicolumn{3}{|l|}{$\circ$ Age } \\
\hline $20-<30$ & 45 & 64.3 \\
\hline $30-<40$ & 24 & 34.3 \\
\hline 40 years and more & 1 & 1.4 \\
\hline \multicolumn{3}{|l|}{ O Sex: } \\
\hline Male & 10 & 14.3 \\
\hline Female & 60 & 85.7 \\
\hline \multicolumn{3}{|l|}{$\circ$ Educational qualification: } \\
\hline BSc. nurse & 10 & 14.3 \\
\hline Associate degree in nursing & 32 & 45.7 \\
\hline Secondary school of nursing (3 years) & 28 & 40.0 \\
\hline \multicolumn{3}{|l|}{$\circ$ Years of experience: } \\
\hline$<3$ years & 17 & 24.3 \\
\hline $3-<6$ years & 21 & 30.0 \\
\hline $6-<9$ years & 10 & 14.3 \\
\hline 9 years and more & 22 & 31.4 \\
\hline \multicolumn{3}{|l|}{$\begin{array}{ll}\circ & \text { Marital status }\end{array}$} \\
\hline Single & 20 & 28.6 \\
\hline Married & 48 & 68.6 \\
\hline Divorced & 1 & 1.4 \\
\hline Widow & 1 & 1.4 \\
\hline \multicolumn{3}{|l|}{$\circ$ Unit } \\
\hline $\mathrm{CCU}$ & 21 & 30.0 \\
\hline $\mathrm{ICU}$ & 22 & 31.4 \\
\hline Emergency unit & 27 & 38.6 \\
\hline
\end{tabular}

Table (2): Comparison between nurses EI domains pre and post training $(n=70)$.

\begin{tabular}{|c|c|c|c|c|c|c|}
\hline \multirow{2}{*}{ Domain } & \multicolumn{2}{|c|}{ Pre EI training } & \multicolumn{2}{|c|}{ Post EI training } & \multirow{2}{*}{$\mathbf{X}^{2}$} & \multirow{2}{*}{ P-value } \\
\hline & $\mathbf{n}$ & $\%$ & $\mathbf{n}$ & $\%$ & & \\
\hline \multicolumn{5}{|l|}{ Emotional Awareness } & \multirow{4}{*}{6.178} & \multirow{4}{*}{$0.046^{*}$} \\
\hline Area for enrichment & 35 & 50.0 & 34 & 48.6 & & \\
\hline Effective functioning & 33 & 47.1 & 26 & 37.1 & & \\
\hline Enhanced skills & 2 & 2.9 & 10 & 14.3 & & \\
\hline \multicolumn{5}{|l|}{ Emotional Management } & \multirow{4}{*}{7.471} & \multirow{4}{*}{$0.024 *$} \\
\hline Area for enrichment & 47 & 67.1 & 31 & 44.3 & & \\
\hline Effective functioning & 20 & 28.6 & 33 & 47.1 & & \\
\hline Enhanced skills & 3 & 4.3 & 6 & 8.6 & & \\
\hline \multicolumn{5}{|l|}{ Social Emotional Awareness } & \multirow{4}{*}{8.187} & \multirow{4}{*}{$0.017^{*}$} \\
\hline Area for enrichment & 24 & 34.3 & 14 & 20.0 & & \\
\hline Effective functioning & 42 & 60.0 & 42 & 60.0 & & \\
\hline Enhanced skills & 4 & 5.7 & 14 & 20.0 & & \\
\hline \multicolumn{5}{|l|}{ Relationship Management } & \multirow{4}{*}{11.133} & \multirow{4}{*}{$0.004 * *$} \\
\hline Area for enrichment & 23 & 32.8 & 10 & 15.7 & & \\
\hline Effective functioning & 41 & 58.6 & 42 & 60.0 & & \\
\hline Enhanced skills & 6 & 8.6 & 18 & 24.3 & & \\
\hline
\end{tabular}


Table (3): Nurses EI level self-assessment score pre and post EI training $(n=70)$.

\begin{tabular}{|c|c|c|c|c|c|c|}
\hline \multirow{2}{*}{ Items } & \multicolumn{2}{|c|}{ Pre EI training } & \multicolumn{2}{|c|}{ Post EI training } & \multirow{2}{*}{ Test } & \multirow{2}{*}{ P-value } \\
\hline & No. & $\%$ & No. & $\%$ & & \\
\hline Low EI level & 26 & 37.1 & 12 & 17.2 & \multirow{3}{*}{$\begin{array}{c}X^{2} \\
11.129\end{array}$} & \multirow[t]{3}{*}{$0.004 * *$} \\
\hline Average EI level & 43 & 61.5 & 50 & 71.4 & & \\
\hline High EI level & 1 & 1.4 & 8 & 11.4 & & \\
\hline $\begin{array}{l}\text { Mean } \pm \text { SD of the quick } \\
\text { emotional intelligence self- } \\
\text { assessment score }\end{array}$ & \multicolumn{2}{|c|}{$99.03 \pm 19.02$} & \multicolumn{2}{|c|}{$111.33 \pm 20.31$} & $\begin{array}{l}T \text { test } \\
3.699\end{array}$ & $0.000 * *$ \\
\hline
\end{tabular}

$* P$. Value is significant at $P<0.05$

** P. Value is highly significant at $P<0.01$

Table (4): Personal characteristics of the studied patients pre and post nurses training ( $n=210$ each group).

\begin{tabular}{|c|c|c|c|c|c|c|}
\hline \multirow{2}{*}{ Item } & \multicolumn{2}{|c|}{ Pre } & \multicolumn{2}{|c|}{ Post } & \multirow{2}{*}{$\mathbf{X}^{2}$} & \multirow{2}{*}{ P-value } \\
\hline & No & $\%$ & No & $\%$ & & \\
\hline \multicolumn{7}{|l|}{ Age (years): } \\
\hline - $\quad 18-<40$ & 77 & 36.7 & 61 & 29.1 & \multirow{3}{*}{20.264} & \multirow{3}{*}{$0.000 * *$} \\
\hline - $\quad 40-<65$ & 87 & 41.4 & 129 & 61.4 & & \\
\hline - 65 and more & 46 & 21.9 & 20 & 9.5 & & \\
\hline Mean \pm SD & \multicolumn{2}{|c|}{$46.11 \pm 19.435$} & \multicolumn{2}{|c|}{$44.03 \pm 15.544$} & & \\
\hline \multicolumn{7}{|l|}{ Gender: } \\
\hline Male & 117 & 55.7 & 118 & 56.2 & \multirow{2}{*}{0.010} & \multirow{2}{*}{0.922} \\
\hline Female & 93 & 44.3 & 92 & 43.8 & & \\
\hline \multicolumn{7}{|l|}{ Education level: } \\
\hline - $\quad$ Illiterate & 9 & 4.3 & 7 & 3.3 & \multirow{5}{*}{4.752} & \multirow{5}{*}{0.314} \\
\hline - $\quad$ Primary & 9 & 4.3 & 16 & 7.6 & & \\
\hline - $\quad$ Preparatory & 30 & 14.3 & 36 & 17.2 & & \\
\hline - $\quad$ Secondary school & 122 & 58.1 & 104 & 49.5 & & \\
\hline - $\quad$ University & 40 & 19.0 & 47 & 22.4 & & \\
\hline \multicolumn{7}{|l|}{ Marital status: } \\
\hline - $\quad$ Single & 60 & 28.6 & 46 & 21.9 & \multirow{4}{*}{19.910} & \multirow{4}{*}{$0.000 * *$} \\
\hline - $\quad$ Married & 109 & 51.9 & 118 & 56.2 & & \\
\hline - $\quad$ Divorced & 0 & 0.0 & 16 & 7.6 & & \\
\hline - $\quad$ Widow & 41 & 19.5 & 30 & 14.3 & & \\
\hline
\end{tabular}

Table 5: Comparison between length of stay in the unit pre and post nurses training ( $n=210$ each group).

\begin{tabular}{|c|c|c|c|c|c|c|}
\hline \multirow{2}{*}{ Item } & \multicolumn{2}{|c|}{ Pre } & \multicolumn{2}{|c|}{ Post } & \multirow{2}{*}{$X^{2}$} & \multirow{2}{*}{ P-value } \\
\hline & No & $\%$ & No & $\%$ & & \\
\hline \multicolumn{7}{|c|}{ Length of stay in the unit: } \\
\hline - $\quad 3-<7$ days & 146 & 69.5 & 185 & 88.1 & \multirow{4}{*}{25.275} & \multirow{4}{*}{$0.000 * *$} \\
\hline - $\quad 7-<15$ days & 43 & 20.5 & 22 & 10.5 & & \\
\hline - $\quad 15-<30$ days & 16 & 7.6 & 3 & 1.4 & & \\
\hline - 30 days or more & 5 & 2.4 & 0 & 0.0 & & \\
\hline
\end{tabular}

$* P$. Value is significant at $P<0.05$

$* * P$. Value is highly significant at $P<0.01$ 
Table (6): Patients' perception of quality nursing care pre and post nurses training ( $n=210$ each group).

\begin{tabular}{|c|c|c|c|c|c|c|}
\hline \multirow{2}{*}{ Item } & \multicolumn{2}{|c|}{ Pre } & \multicolumn{2}{|c|}{ Post } & \multirow{2}{*}{$X^{2}$} & \multirow{2}{*}{ P-value } \\
\hline & No & $\%$ & No & $\%$ & & \\
\hline - $\quad$ Strongly disagree & 2 & 1.0 & 3 & 1.4 & \multirow{5}{*}{14.713} & \multirow{5}{*}{$0.005^{*}$} \\
\hline - $\quad$ Disagree & 16 & 7.6 & 6 & 2.9 & & \\
\hline - $\quad$ Neutral & 83 & 39.5 & 60 & 28.6 & & \\
\hline - $\quad$ Agree & 87 & 41.4 & 101 & 48.1 & & \\
\hline - Strongly agree & 22 & 10.5 & 40 & 27.1 & & \\
\hline Total agreement of PPNCS & 109 & 51.9 & 141 & 67.1 & 83.161 & $\mathbf{0 . 0 0 0} * *$ \\
\hline Mean \pm SD. of PPQNCS & \multicolumn{2}{|c|}{$46.67 \pm 10.99$} & \multicolumn{2}{|c|}{$54.82 \pm 10.93$} & $T$ test 7.623 & $0.000 * *$ \\
\hline
\end{tabular}

Table (7): Correlation between nurses' EI and patients' perception of quality nursing care.

\begin{tabular}{|c|c|c|}
\hline Item & r & P-value \\
\hline Nurses' EI and patients' perception of quality nursing care. & 0.767 & $0.000^{* *}$ \\
\hline P. Value is significant at $P<0.05 \quad * * P$. Value is highly significant at $P<0.01$
\end{tabular}

Table (1): Reveals the personal data for studied nurses, the majority of studied nurses $85.7 \%$ were females, $68.6 \%$ was married, $64.3 \%$ for studied nurses had $20-<30$ years, $38.6 \%$ working at emergency unit and $31.4 \%$ for nurses had experience for 9 years and more.

Table (2): Shows that there were significant relation between pre and post training in relation to domains of EI namely: emotional awareness, emotional management, and social emotional awareness $\mathrm{X}^{2}$ was $6.178,7.471$ and 8.187 respectively at $\mathrm{P}<0.05$. In addition there was highly significant relation between pre and post training in relation to relationship management domain $\mathrm{X}^{2}$ was 11.133 at $\mathrm{P}<0.01$.

Table (3): Reveals that the highest percentages of nurses EI level were $61.5 \%$ and $71.4 \%$ for average EI level in relation to pre and post EI training respectively. There was highly significant correlation between nurses EI level in relation to pre and post EI training $\mathrm{X}^{2}$ was 11.129 at $\mathrm{P}<0.01$. For the quick emotional intelligence self-assessment score Mean \pm SD were $99.03 \pm 19.02$ and $111.33 \pm 20.31$ in relation to pre and post EI training respectively. There was highly significant relation $\mathrm{T}$ test was 3.699 at $\mathrm{P}<$ 0.01 .

Table (4): Regarding to critical ill patient's personal characteristic the table revealed that the highest percentage: for age was $41.4 \%$ and $61.4 \%$ for patients had $40-<65$ years old, gender was $55.7 \%$ and $56.2 \%$ for male patients, education level was $58.1 \%$ and $49.5 \%$ for patients had secondary school, and marital status was $51.9 \%$ and $56.2 \%$ for married patients respectively in relation to pre and post nurses training. There was highly significant correlation for age and marital status in relation to pre and post nurses training $\mathrm{X}^{2}$ was 20.264 and 19.910 respectively at $\mathrm{P}<0.01$.
Table (5): Declares that the highest percentage of patient's length of stay in the unit was $69.5 \%$ and $88.1 \%$ for patients length of stay $3-<7$ days in relation to pre and post nurses training respectively. There was highly significant correlation $\mathrm{X}^{2}$ was 25.275 at $\mathrm{P}<0.01$.

Table (6): Regarding the differences in patients' perception of quality nursing care, the table revealed that the highest percentage was $51.9 \%$ and $67.1 \%$ for the total agreement of PPNCS in relation to pre and post nurses training respectively. There was highly significant correlation $\mathrm{X}^{2}$ was 83.161 at $\mathrm{P}<0.01$. For the Mean \pm SD of the total score of patients' perception of quality nursing care it was $46.67 \pm 10.99$ pre and $54.82 \pm 10.93$ post nurses training. There was highly significant correlation $\mathrm{T}$ test was 7.623 at $\mathrm{P}<0.01$.

Table (7): Regarding Pearson correlation between nurses' EI and patients' perception of quality nursing care the table revealed that there was highly significant correlation $\mathrm{r}=0.767$ at $\mathrm{P}<0.01$.

\section{Discussion}

Quality Patient care requires excellent technical services and good management and coordination efforts, in addition to it demands respectful and responsive care to patient's needs, preferences, and values; make clinical decisions that guided by patient values; and provide patients with emotional support (Rego et al., 2010). Highly emotionally intelligent people will be aware about their emotions, strengths, and weakness; also their ability to regulate emotion and problems solving will be enhanced (Mousa et al., 2017) Some of the nursing staff is not aware of the emotional intelligence concept or able to identify how they can best manage their own emotions. 
Different activities and strategies may be of benefit and could help (Wilson, 2014).

As found in the present study there were significant relation between emotional awareness, emotional management and social awareness domains of EI pre and post training. Moreover there was highly significant relation between relationship management domain of EI pre and post training. Which means that emotional intelligence is markedly tends to be improved by training and continuity in application. The finding is supported by Shahnavazi et al., (2018) who studied the effect of the EI education on quality of life in hemodialysis patients revealed that all domains of EI significantly improved after training.

The current study results showed that the nurses EI level were average for pre and post EI training. There was highly significant relation between pre and post EI training. As there wasn't previous attempts to develop or improve nurses EI so the level was average. In addition it is expected that repeated training will more enhance EI level. In the same line of the current study Codier et al., (2013) study of developing EI in oncology nurses found that post study improvements in emotional care documentation and emotional care planning suggest a positive effect of EI training.

In addition Gilar-Corbí, (2018) study to reveal if the emotional competence be taught in higher education clarified that EI training program introduced in three modalities: classroom, online, and coaching for three groups was effective in the all of the modalities. Moreover Al Faouri, (2014) who studied the effect of EI training on nurses' job satisfaction added that the training significantly increased emotional intelligence scores.

The present study finding revealed that there was highly significant correlation in patients' perception of quality nursing care in relation to pre and post nurses training. As emotionally intelligent nurses deal with patients while be pleased, reacting, polite, fair, sensitive, and approachable. All these characters increase the patients' perception of quality nursing care. A study of Yeşil et al., (2015) who investigated the patients' perceptions of quality nursing care (PPQNC) in intensive care unit was in accord with the current study. Found that PPQNC scores were high and patient's satisfaction levels with the nursing care they received were good.

Moreover Adam et al., (2017) to declare the quality of nursing care as perceived by cancer patients found that the overall means for the quality of nursing care were high. In addition Reck, (2010) to show patients' expectations and satisfaction with nursing care stated that the vast majority of the studied patients were highly satisfied. While Celik, (2017) to detect the relationship between patient satisfaction and EI skills of nurses added that the levels of the patients' satisfaction with the nursing care provided were found to be high.

From study finding there was highly significant relation between nurses' EI and patients' perception of quality nursing care. That is the end result which proves the study hypothesis. The current study results are supported by Thorsteinsson, (2002) study of the quality of nursing care as perceived by chronic illnesses patients reported that nurses giving high quality care possessed attributes such as kindness, a good attitude and manner, as well as clinical competence. In addition Rao, (2006) in his study on leaders EI declares that a high degree of emotional intelligence linked to strong performance.

In the same line Ezzatabadi et al., (2012) to found the impact of nurses' emotional on the quality of hospital services indicated that nursing staffs' EI has a direct effect on the services quality. Moreover Celik, (2017) to reveal the relationship between patient satisfaction and EI skills of nurses found that there was positive relationship between the high levels of EI of the nurses and the high levels of patient satisfaction. While the current study contradicts with Chao et al., (2016) study to show nurse occupational burnout and patient-rated quality of care reported that EI among nurses was not significantly correlated with quality of care as assessed by the patients.

\section{Conclusions}

The current study concluded that there was significant difference relation between domains of EI namely: emotional awareness, emotional management and social awareness. Further there was highly significant deference for relationship management domain. There was marked improvement in quick emotional intelligence selfassessment score. The EI training had positive effect on length of patients staying in Critical Care Units. Nurses EI had positive effect on patients' perception of quality nursing care.

\section{Recommendation}

Based on the results the study recommended that emotional intelligence training should be introduced for critical care nurses as a basic of in-service training programs as an indicator for improvement of quality nursing care for critically ill patients.

\section{References}

1. Adam, C., Patiraki, E., Lemonidou, C., Radwin, L., Charalambous, A., Charalambous, M., Berg, A., Sjövall, K., Katajisto, J., Stolt, M., \& Suhonen, R., 
(2017): Quality of nursing care as perceived by cancer patients: A cross-sectional survey in four European countries. JBUON, Vol. (22), No. (3), Pp. 777-782.

2. Al Faouri, I., Al Ali, N., \& Al Shorman, B., (2014): The Influence of Emotional Intelligence Training on Nurses' Job Satisfaction among Jordanian Nurses. European Journal of Scientific Research, Vol. (4), Pp. 486-494.

3. Al-Hamdan, Z., Oweidat, IA., Al-Faouri, I., \& Codier, E., (2017): Correlating Emotional intelligence and job performance among Jordanian hospitals' registered nurses. Nurs Forum, Vol. (52), No. (1), Pp. 12-20.

4. Al-Hussami, M., Al-Momani, M., Hammad, S. Maharmeh, M., \& Darawad, M., (2017): Patients' perception of the quality of nursing care and related hospital services. Health and Primary Care, Vol. (1), No. (2), Pp. 1-6.

5. Celik, G. (2017): The relationship between patient satisfaction and emotional intelligence skills of nurses working in surgical clinics. Patient Preference and Adherence, Vol. (11), Pp. 1363-1368.

6. Cerit, E., \& Gordeles, N., (2014): Levels of emotional intelligence of nursing students. Int $\mathbf{J}$ Caring Sci., Vol. (7), No. (3), Pp. 936-45.

7. Chao, M., Shih, C., \& Hsu, S., (2016): Nurse occupational burnout and patient-rated quality of care: The boundary conditions of emotional intelligence and demographic profiles. Japan Journal of Nursing Science, Vol. (13), Pp. 156165.

8. Codier, E., Freitas, B., \& Muneno, L., (2013): Developing Emotional Intelligence Ability in Oncology Nurses: A Clinical Rounds Approach. Oncology Nursing Forum, Vol. (40), No. (1), Pp. 22-29.

9. Daniels, L., Johnson, A., Cornelius, P., Bowron, C., Lehnertz, A., Moore, M., Shen, Y., Schulte, P., Pendegraft, R., Hall, K., \& Bauer P., (2018): Improving Quality of Life in Patients at Risk for Post-Intensive Care Syndrome. Mayo Clin Proc Innov Qual Outcomes, Vol. (2), No. (4), Pp. 359-369.

10. Dikmen, Y., \& Yllmaz, D., (2016): Patient's Perceptions of Nursing Care-A Descriptive Study from Turkey. Ann Nurs Pract, Vol. (3), No. (3), Pp. 1048.

11. Driscoll, A., Grant, M., Carroll, D., Dalton, S., Deaton, C., Jones, I., Lehwaldt, D., McKee, G., Munyombwe, T., \& Astin, F., (2018): The effect of nurse-to-patient ratios on nurse-sensitive patient outcomes in acute specialist units: a systematic review and meta- analysis. European Journal of Cardiovascular Nursing, Vol. (17), No. (1), Pp. 6 -22.

12. Ezzatabadi, M., Bahrami, M., Hadizadeh, F., Arab, M., Nasiri, S., Amiresmaili, M., \& Tehrani, G., (2012): Nurses' emotional impact on the quality of hospital services, Iranian Red Cresent Medical Journal, Vol. (14), No. (12), Pp. 758-763.

13. Gilar-Corbí, R., Pozo-Rico, T., Sánchez, B., \& Castejón, J., (2018): Can Emotional Competence Be Taught in Higher Education? A Randomized Experimental Study of an Emotional Intelligence Training Program Using a Multimethodological Approach. Front $\begin{array}{llll}\text { Psychol., } & \text { Vol. } & \text { (9), } & \end{array}$ doi: 10.3389/fpsyg.2018.01039

https://www.ncbi.nlm.nih.gov/pmc/articles/PM C6030676/

14. Hajibabaee, F., Farahani, M., Ameri, Z., Salehi, T., \& Hosseini, F., (2018): The relationship between empathy and emotional intelligence among Iranian nursing students. Int J Med Educ., Vol. (9), Pp. 239-243.

15. Liu, Y., Wang, Z., \& Lü, W., (2013): Resilience and affect balance as mediators between trait emotional intelligence and life satisfaction. Personality and Individual Differences، Vol. (54), No. (7), Pp. 850-855.

16. Meehan, M., Taylor, B., \& Maiden, J., (2015): Called to Caring: A Tool to Assess Awareness and Attitudes in Baccalaureate Nursing Students at Point Loma Nazerene University. Master thesis of science in nursing. Faculty of the School of Nursing, Point Loma Nazarene University. https://www.whdl.org/sites/default/files/Called $\% 20$ to\%20Caring\%20A\%20Tool\%20to\%20Ass ess $\% 20$ Awareness $\% 20$ and $\% 20$ Attitudes $\% 20$ in $\% 20$ Baccalaureate $\% 20$ Nursing\%20Students.pdf

17. Mousa, A., Menssey, R., \& Kamel, N., (2017): Relationship between Perceived stress, Emotional Intelligence and Hope among Intern Nursing Students. IOSR-JNHS. Vol. (6), Issue (3), Ver. (II), Pp. 75-83.

18. Rao, P., (2006): Emotional intelligence: the Sine Qua Non for a clinical leadership toolbox. J Commun Disord., Vol. (39), No. (4): Pp. 310319.

19. Reck, D., (2010): Patients' Expectations and Satisfaction with Nursing Care, and Their Nurses' Awareness of Their Expectations. PhD Dissertation, School of Nursing, the Graduate School, the Pennsylvania State University. https:/etda.libraries.psu.edu/files/final_submissi ons/1674 
20. Rego, A., Godinho, L., McQueen, A., \& Cunha, M., (2010): Emotional intelligence and caring behaviour in nursing, The Service Industries Journal, Vol. (30), No. (9), Pp. 14191437.

21. Rezaei, S., \& Salehi, S., (2018): A Study of the Relationship between Emotional Intelligence and Patient Safety Culture among Emergency Nurses in Selected Hospitals in Shiraz in 2017, J Res Med Dent Sci, Vol. (6), No. (2), Pp. 276283.

22. Scholtz, S., Nel1, E., Poggenpoel, M., \& Myburgh, C., (2016): The Culture of Nurses in a Critical Care Unit. Global Qualitative Nursing Research. Vol. (3), Pp. 1-11.

23. Senarath, U., \& Gunawardena, N., (2011): Development of an Instrument to Measure Patient Perception of the Quality of Nursing Care and Related Hospital Services at the National Hospital of Sri Lanka. Asian Nursing Research, Vol. (5), No. (2), Pp. 71-80.

24. Shahnavazi, M., Parsa-Yekta, Z., Yekaninejad, M., Amaniyan, S., Griffiths, P. \& Vaismoradi, M., (2018): The effect of the emotional intelligence education programme on quality of life in haemodialysis patients. Applied. Nursing Research, Vol. (39), Pp. 1825.

25. Shorofi, S., Jannati, Y., Moghaddam, H., \& Yazdani-Charati, J., (2016): Psychosocial needs of families of intensive care patients: Perceptions of nurses and families. Niger Med J., Vol. (57) No. (1), Pp. 10-18.

26. Sun, H., \& Okochili M., (2017): Patient's perception of the nurse-patient relationship in Postoperative care. Bachelor's thesis. JAMK University of Applied Sciences. https://www.theseus.fi/bitstream/handle/10024/ 141453/THESIS\%20Okochili\%20Sun\%20Bach elors $\% 20$ Final $\% 20 B N$..pdf? sequence $=1 \&$ is Allo wed=y

27. Thorsteinsson, L., (2002): The quality of nursing care as perceived by individuals with chronic illnesses: the magical touch of nursing. Journal of Clinical Nursing, Vol. (11), Pp. 3240.

28. University of Minnesota Extension: Center for Youth Development: Quick Emotional Intelligence Self-Assessment. SEL TOOLKIT, Pp. 33-35. Retrieved on $7^{\text {th }}$ May 2017 at 5pm. https:/conservancy.umn.edu/bitstream/handle/1 1299/195791/emotional-intelligence-selfassessment.pdf?sequence $=1 \&$ is Allowed $=y$

29. Vahedian-Azimi, A., Ebadi, A., Saadat, S., \& Ahmadi, F., (2015): Intelligence Care: A Nursing Care Strategy in Respiratory Intensive
Care Unit. Iran Red Crescent Med J., Vol, (17), No. (11), e20551. doi: 10.5812/ircmj.20551. https://www.ncbi.nlm.nih.gov/pmc/articles/PM C4698142/

30. Weilenmann, S., Schnyder, U., Parkinson, B., Corda, C., von Känel, R., \& Pfaltz, M., (2018): Emotion Transfer, Emotion Regulation, and Empathy-Related Processes in PhysicianPatient Interactions and Their Association With Physician Well-Being: A Theoretical Model. Frontiers in Psychiatry; Vol. (9), Pp. 389. doi: 10.3389/fpsyt.2018.00389.

31. Wergin, R., \& Modrykamien, A., (2012): Cognitive Impairment in ICU Survivors: Assessment and Therapy. Cleveland Clinic Journal of Medicine, Vol. (79), No. (10), Pp. 705-712.

32. Wilson, J., (2014): The awareness of emotional intelligence by nurses and support workers in an acute hospital setting. Journal of Health Sciences, Vol. (2), No. (9), Pp. 458-464.

33. Yeşil, P., Öztunç, G., Eskimez, Z., ,Tanriverdi, G., \& Köse, I., (2015): An Investigation of Patients Perceptions of Nursing Care: Case of Intensive Care. International Journal of Caring Sciences, Vol. (8), No. (2), Pp. 412-419. 